\title{
Purification of model biogas from toluene using deep eutectic solvents
}

\author{
Edyta Słupek ${ }^{1, *}$, Patrycja Makoś ${ }^{1}$, Jacek Gębicki ${ }^{1}$, and Andrzej Rogala ${ }^{1}$ \\ ${ }^{1}$ Gdańsk University of Technology, Faculty of Chemistry, Department of Process Engineering \\ and Chemical Technology, ul. Narutowicza 11/12, 80-233 Gdańsk, Poland
}

\begin{abstract}
Biogas from landfills and wastewater treatment facilities typically contain a wide range of volatile organic compounds (VOCs), that can cause severe operational problems when biogas is used as fuel. Among the contaminants commonly occur aromatic compounds, i.e. benzene, ethylbenzene, toluene and xylenes (BTEX). In order to remove BTEX from biogas, different processes can be used. A promising process for VOCs removal is their absorption in deep eutectic solvents (DES). In this work, three DES: ([ChCl] U TEG - [choline chloride]:urea:tetraethylene glycol (1:2:2), [ChCl] U - [choline chloride]:urea (1:2), [ChCl] DEG [choline chloride]:diethylene glycol (1:2)) and water were tested to toluene absorption in concentration of $2000 \mathrm{ppm} \mathrm{v/v} \mathrm{in} \mathrm{nitrogen} \mathrm{stream.} \mathrm{The}$ results demonstrated the high absorption capacity of toluene using DES based on glycols.
\end{abstract}

\section{Introduction}

Biogas can be obtained in anaerobic digestion by using waste materials such as sewage or landfill. The biogas which consists of 50-75\% methane and 25-50\% carbon dioxide, the remaining compounds (about 1-1.5\%) are pollutions, which must be removed before converting biogas into energy. Currently, confirmed contamination in biogas are compounds such as ammonia, hydrogen sulfide, linear hydrocarbons (HC), aromatic hydrocarbons i.e. benzene, ethylbenzene, toluene and xylenes (BTEX), halogen compounds and siloxane [1-3]. Table 1 demonstrated an example of the composition of biogas from wastewater treatment plant [1].

Applied biogas purification technologies are based on adsorption, absorption, biological methods, membranes technologies, cooling or processes using various types of catalysts [4-6].

In recent years, a new class of solvents called deep eutectic solvents (DES) has emerged, which are "green" alternative to the conventional solvents used to absorption of impurities from biogas. DESs are obtained by mixing typically quaternary ammonium salts being hydrogen bond acceptors (HBA) with hydrogen bond donors (HBD) with appropriate molar ratios [7, 8]. The resulting homogeneous liquid products have many similar properties to ionic liquids (ILs), but they are less toxic, more biodegradable and their

\footnotetext{
*Corresponding author: edyta.slupek@pg.edu.pl
} 
synthesis are cheaper and simpler than ILs. The first DES was composed of choline chloride $(\mathrm{ChCl})$ and urea $(\mathrm{U})$ in 1:2 molar ratio and is currently the best-studied DES and most commonly used in various processes [9]. The wide selection and high availability of HBAs and HBDs cause rapid development of DES. In recent years, DESs have been widely used in electrochemistry [10], nanotechnology [11], catalysis [12], separation processes [13], analytical chemistry $[14,15]$ etc.

Table 1. Biogas composition [1].

\begin{tabular}{|c|c|c|c|}
\hline Family & Compound & Range & Units \\
\hline Major & Metane & $55.1-57.8$ & $\%$ \\
\hline Major & Carbon dioxide & $25.5-32.5$ & $\%$ \\
\hline Inorganic & Hydrogen sulfide & $15.54-2582.95$ & $\mathrm{mg} / \mathrm{m}^{3}$ \\
\hline Organic sulphur & Methyl mercaptan & $0.3-0.7$ & $\mathrm{mg} / \mathrm{m}^{3}$ \\
\hline Organic Sulphur & Ethyl mercaptan & $0.1-0.8$ & $\mathrm{mg} / \mathrm{m}^{3}$ \\
\hline Alkanes & Sum of linear HC & $29.3-44.0$ & $\mathrm{mg} / \mathrm{m}^{3}$ \\
\hline Aromatic & Sum BTEX & $3.5-4.4$ & $\mathrm{mg} / \mathrm{m}^{3}$ \\
\hline Organic silicon & Sum of siloxanes & $3.4-4.5$ & $\mathrm{mg} / \mathrm{m}^{3}$ \\
\hline
\end{tabular}

Biogas purification with absorptions methods is based on diffusion of mass transfer by dissolving gaseous impurities that are absorbed directly in the solvent liquid. In the case of biogas purification from hydrophobic compounds (BTEX - e.g. toluene), water cannot be used as an absorbent. The literature suggests the use of absorbents such as high-boiling absorbents, water-solid suspensions or water-oil emulsions [16]. The used absorbents should have high absorption capacity for a wide range of VOCs. The low viscosity and high diffusion coefficient affect the absorption kinetics. While the low vapour pressure of the absorbents used prevents the additional problems of air pollution. The most important criterion in the selection of new absorbents for biogas purification is their easy availability, low cost, and low toxicity. Until now, ionic liquids (ILs) have been used as green absorbents for purification, but more and more attention is paid to deep eutectic solvents (DES). ILs and DESs have similar physicochemical properties, however, DESs has several advantages compared to traditional ILs. One of the main advantages of DESs is their synthesis, which consists of simply mixing two or three components (easily available chemicals). While the preparation of most ionic liquid is a complicated [17-19]. At the moment there is much paper on the toxicity of ionic liquids [20, 21]. Most DESs are also biodegradable and non-toxic. The paper describes for an application of DESs composed of choline chloride, glycols (tetraethylene glycol and diethylene glycol) and urea for removal of toluene from model biogas.

\section{Experimental}

\subsection{Materials}

\subsubsection{Reagents}

The chemicals used for model biogas preparation such as toluene (purity $\geq 99 \%$ ) was purchased from POCH (Poland), nitrogen (purity N 5.5) was purchased from Linde Gas 
(Poland). For DES synthesis choline chloride ( $\mathrm{ChCl})$, urea (U), diethylene glycol (DEG), tetraethylene glycol (TEG) (purity $\geq 99 \%$ ) were purchased from Sigma-Aldrich (USA).

\subsubsection{Aparatures}

Gas chromatograph Autosystem XL equipped with a flame ionization detector (FID) (PerkinElmer, USA) and HP-5ms (30 $\mathrm{m} \times 0.25 \mathrm{~mm} \times 0.25 \mu \mathrm{m})$ capillary column (Agilent, USA) and TurboChrom 6.1 software (PerkinElmer, USA) were used in the investigations. FT-IR spectra were obtained using a Bruker Tensor 27 spectrometer (Bruker, USA) with an ATR accessory and OPUS software (Bruker, USA). Dynamic viscosity was determined using BROOKFIELD LVDV-II + viscometer (Labo-Plus, Poland).

\subsection{Methods}

\subsubsection{Chromatographic analysis}

The following conditions were used for the GC-FID analysis: injection port temperature $150^{\circ} \mathrm{C}$, injection mode: split $(10: 1)$, detector temperature $220^{\circ} \mathrm{C}$, detector gases flow rates: air $450 \mathrm{~mL} / \mathrm{min}$, hydrogen $45 \mathrm{~mL} / \mathrm{min}$, carrier gas (nitrogen) flow rate $2 \mathrm{~mL} / \mathrm{min}$ and oven temperature $100^{\circ} \mathrm{C}$.

\subsubsection{FT-IR analysis}

FT-IR spectra of pure compounds and DESs were taken using attenuated total reflectance (ATR) with the following operating parameters: spectral range $4000-600 \mathrm{~cm}^{-1}$, resolution: $4 \mathrm{~cm}^{-1}$, number of sample scans: 64 , number of background scans: 64 , slit width: $0.5 \mathrm{~cm}$, $100 \mu \mathrm{L}$ of DES was used for IR scan.

\subsubsection{DES preparation and determination of viscosity and density}

DES were synthesized by combining $\mathrm{ChCl}$ with $\mathrm{DEG}$ with a mole ratio of $1: 2,[\mathrm{ChCl}]$ $\mathrm{U}(1: 2)$ and $[\mathrm{ChCl}] \mathrm{U}$ TEG $(1: 2: 2)$. Next, the mixtures were stirred magnetically at $80^{\circ} \mathrm{C}$ until homogeneous liquids were obtained. The liquids were then left to cool spontaneously to room temperature.

The chemical structures of the used compounds for the synthesis of DES are shown in Table 2. The structures were made in MDL ISIS DRWA 2.5.

Table 2. Chemical formula of used chemical compounds for DES syntheses.

\begin{tabular}{|c|c|c|}
\hline Chemical name & Abbreviation & Chemical formula \\
\hline Choline chloride & $\mathrm{ChCl}$ & 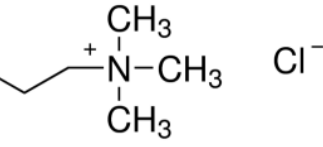 \\
\hline Urea & $\mathrm{U}$ & $\stackrel{\mathrm{O}}{\mathrm{NH}_{2}-\stackrel{\mathrm{II}}{\mathrm{C}}-\mathrm{NH}_{2}}$ \\
\hline Tetraethylene glycol & TEG & \\
\hline Diethylene glycol & DEG & $\mathrm{OH}$ \\
\hline
\end{tabular}


Deep eutectic solvents including [ChCl] U (1:2), [ChCl] U TEG (1:2:2) and [ChCl] DEG (1:2) are listed in Table 3 where their basic physico-chemical parameters are compared, such as: density, viscosity and surface tension All parameters were determined at $25^{\circ} \mathrm{C}$.

Table 3. Physicochemical properties.

\begin{tabular}{|c|c|c|c|}
\hline \multirow{2}{*}{ DES } & Density & Viscosity & \multirow{2}{*}{ Ref. } \\
\cline { 2 - 4 } & {$\left[\mathrm{g} / \mathrm{cm}^{3}\right]$} & {$[\mathrm{cP}]$} & \\
\hline$[\mathrm{ChCl}] \mathrm{U}(1: 2)$ & 1.25 & 403.2 & {$[7]$} \\
\hline$[\mathrm{ChCl}] \mathrm{DEG}(1: 2)$ & 1.12 & 52.5 & {$[16]$} \\
\hline$[\mathrm{ChCl}] \mathrm{U}$ TEG $(1: 2: 2)$ & 1.17 & 380.9 & This study \\
\hline Water & 0.997 & 8.9 & This study \\
\hline
\end{tabular}

\subsection{Absorption of toluene from model biogas}

For the studies, $2 \mathrm{~mL}$ of liquid toluene was used, which was bubbled with a constant nitrogen flow of $5 \mathrm{~mL} / \mathrm{min}$ at $25^{\circ} \mathrm{C}$. The gas phase toluene was diluted with nitrogen to a concentration of $2000 \mathrm{ppm} \mathrm{v} / \mathrm{v}$. The total flow of nitrogen and gaseous toluene was kept constant at $25 \mathrm{~mL} / \mathrm{min}$. Total volume of DES was $30 \mathrm{~mL}$. The concentration of toluene gas was monitored at the inlet and outlet of the bubble column using gas chromatography technique. The processes were carried out for 90 minutes.

The same procedure for the purification of model gas from gaseous toluene was performed for DES:

- $\quad[\mathrm{ChCl}] \mathrm{U}$ in a molar ratio of $1: 2$

- $\quad[\mathrm{ChCl}]$ DEG in a molar ratio of $1: 2$

- $\quad[\mathrm{ChCl}] \mathrm{U}$ TEG in a molar ratio of 1:2:2

- Water.

Removal efficiency of toluene was calculate using Eq. (1).

$$
R E=\left(C_{0}-C\right) / C_{0} \cdot 100 \%
$$

Where $C_{0}$ is the initial concentration (ppm v/v) of the toluene in the vapor phase, $C$ is the final concentration of toluene after absorption process ( $\mathrm{ppm} \mathrm{v} / \mathrm{v})$.

\section{Result and Discussion}

\subsection{FTIR studies}

An effective analytical technique for determining functional groups present in newly synthesized compounds is FT-IR. The presence of vibrations of the tensile bond from the hydroxyl group occurs in the region of 3700-3100 $\mathrm{cm}^{-1}$. Depending on the hydrogen bond strength between HBA and HBD in DES, the hydroxyl bond band may change its location to higher or lower wave numbers. FTIR spectra for the synthesized DES were made and compared with DES after the toluene purification step (Fig.1). The results indicate the FTIR DES + toluene spectra change in the vibration area $680-750 \mathrm{~cm}^{-1}$, which confirms the absorption of toluene in [ChCl]DEG (1:2) and [ChCl]U TEG (1:2:2). There are no characteristic toluene peaks on the water and $[\mathrm{ChCl}] \mathrm{U}$ spectra, which indicate low absorption of toluene. 


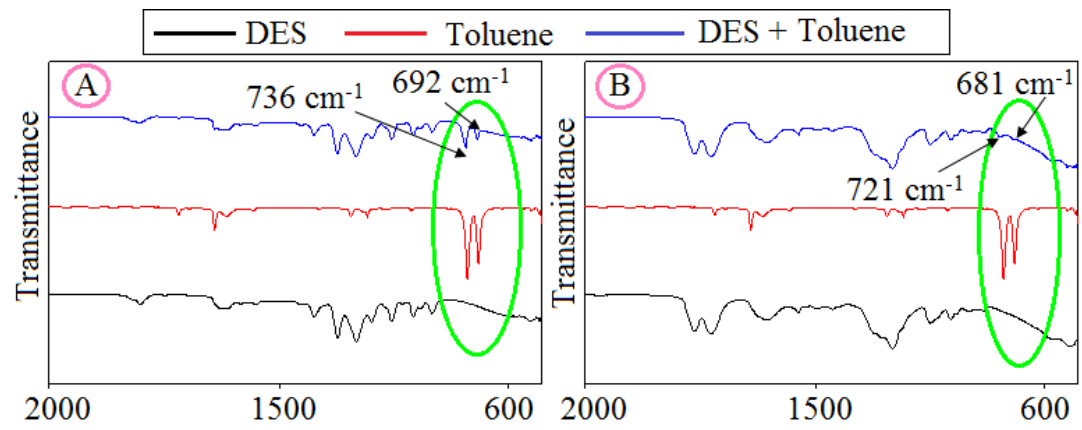

Wavennumber $/ \mathrm{cm}^{-1}$
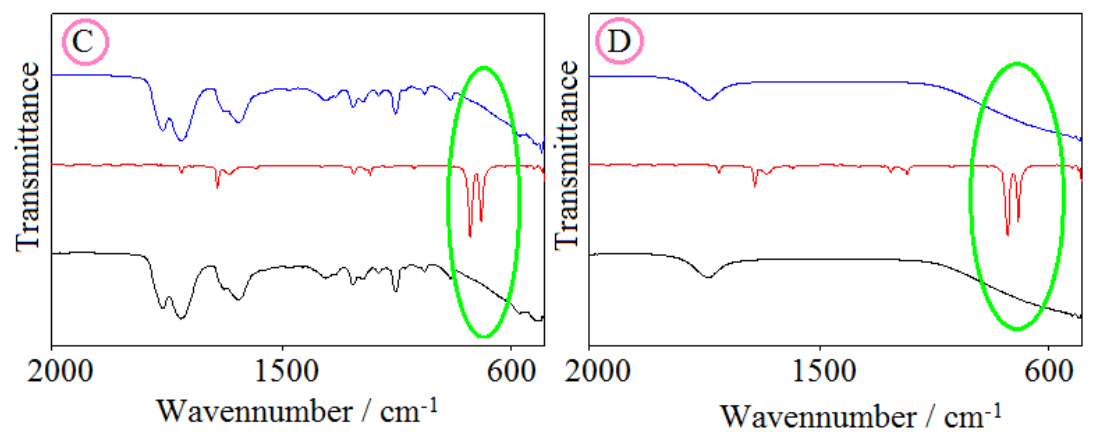

Fig. 1. FT-IR spectra of pure DES, toluene and DES after absorption process for A) [ChCl] U TEG $(1: 2: 2), \mathrm{B})[\mathrm{ChCl}] \mathrm{DEG}(1: 2), \mathrm{C})[\mathrm{ChCl}] \mathrm{U}(1: 2), \mathrm{D})$ water.

\subsection{Absorption of toluene in different absorbent}

There are many compounds from the volatile organic compounds (VOCs) group that occur as biogas contaminants from wastewater treatment plants and landfill $[23,24]$. The main VOCs include aromatic compounds, alkanes, ketones and esters [1]. In this work, toluene was used as model contamination of biogas due to the common occurrence in various types of biogas. Physicochemical properties, as well as structures of both DES and VOCs, should be taken into account during absorption process. The main parameters affecting absorption efficiency include density, viscosity, hydrophobic or hydrophilic nature and polarity.

Fig. 2 shows the sorption curves of toluene with four types of absorbents. The results indicate that the highest efficiency of toluene absorption was obtained with the use of [ChCl] DEG $1: 2$ molar ratio. Comparable results were obtained for [ChCl] U TEG (1:2:2), for water and $[\mathrm{ChCl}] \mathrm{U}(1: 2)$, much worse results were obtained.

One of the parameters affecting the efficiency of removal of toluene from the gas phase in the absorption process is a viscosity. In DES with a high viscosity, an increase in bubble diameter was observed (Fig. 3), which can affect the efficiency of the absorption process. The obtained results indicate that viscosity is not a parameter that mainly determines the efficiency of the absorption process.

Water, which has the lowest viscosity values, showed the worst absorption efficiency due to the poor solubility of toluene. Similar results were obtained for the most common DES composed of $\mathrm{ChCl}$ and $\mathrm{U}(1: 2)$. Thus, water and $[\mathrm{ChCl}] \mathrm{U}(1: 2)$ is not a suitable absorbent for removing hydrophobic and non-polar VOCs. The main parameter determining the removal of toluene from the gas phase is its solubility in the absorbent Fig. 4 demonstrated average removal of toluene in the absorption process. 


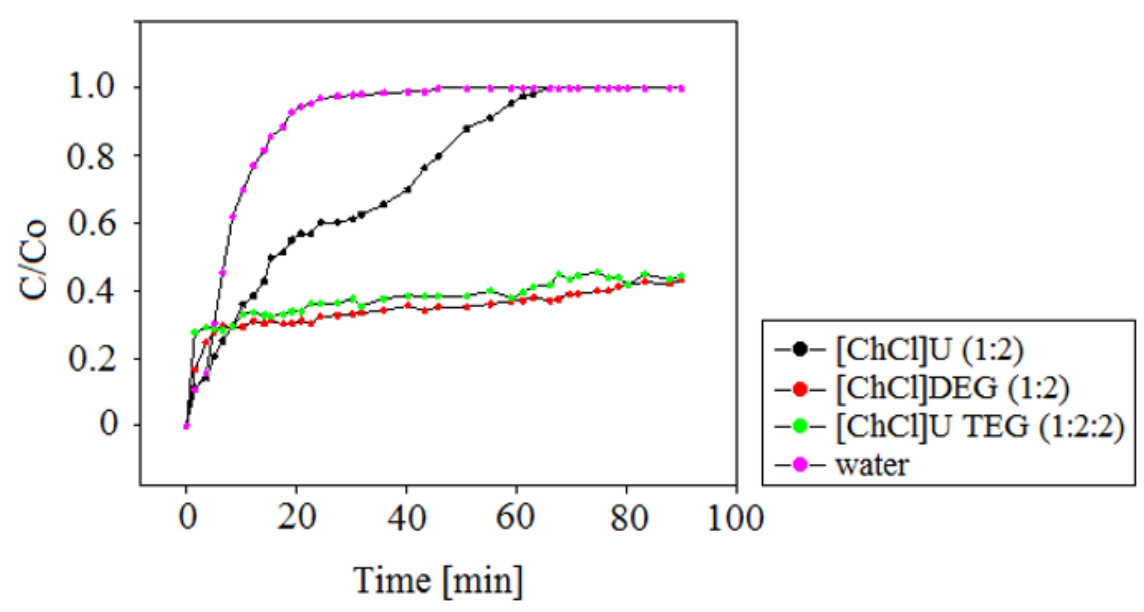

Fig. 2 Experimental breakthrough curves of toluene at different absorbents.

A

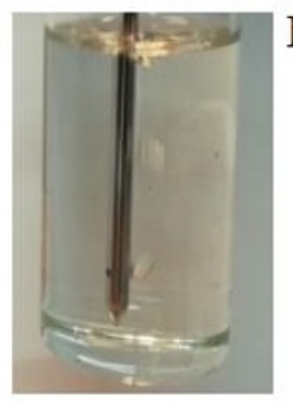

B

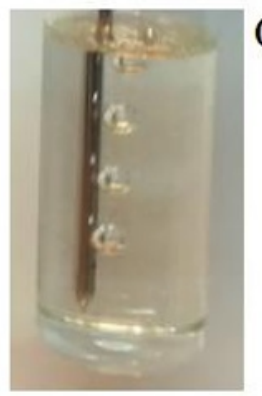

C

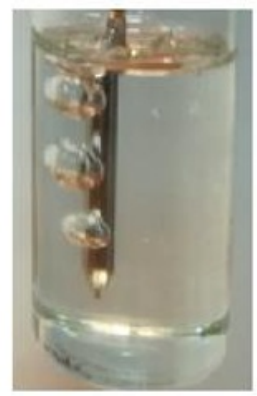

Fig. 3 DES photography during the absorption process A) [ChCl] DEG (1:2), B) [ChCl] U (1:2), C) $[\mathrm{ChCl}]$ U TEG $(1: 2: 2)$.

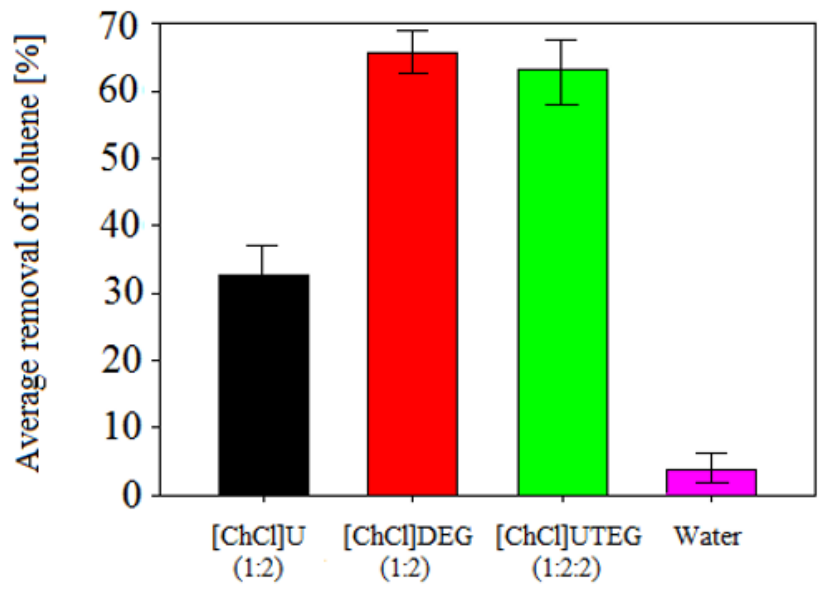

Fig. 4 Average removal of toluene from model biogas during $90 \mathrm{~min}$ of absorption process. 
The addition of glycols to DES significantly improves the sorption capacity of the absorbent. After 90 minutes of the process, in the DES containing glycols, no supersaturation was achieved. The process can be carried out much longer with maintaining high absorption process efficiency.

\section{Conclusion}

The paper presents an effective and rapid absorption method based on eco-friendly deep eutectic solvents. The deep eutectic solvents have proven to be suitable solvents for various absorption processes. Compared to traditional organic solvents and ILs.

Three DES and water were used to removal of toluene from model biogas under laboratory conditions. These results show that DES based on glycols ([ChCl] DEG 1:2 and [ChCl] U TEG 1:2:2) have a better absorption capacity than water and most popular DES ([ChCl] U 1:2 molar ratio).

Currently, in the literature there are no papers describes the application of DES for the absorption of BTEX from gas phases. However, one can find several studies on the absorption of toluene by means of ionic liquids. Experimental toluene breakthrough curves on five absorbents including ILs (1-methyl-2-pyrrolidonium hydrogen sulphate - [Hnmp] HSO4, 1-ethyl-3-methylimidazolium hexafluorophosphate - [Emim] PF6, 1-ethyl-3methylimidazolium tetrafluoroborate [Emim] BF4) and H2O + Tween-80 (polyoxyethylene sorbitan monooleate) show that after the first 90 minutes of the process all absorbents show almost $100 \%$ saturation with toluene [27]. In our research, we obtained better results, because, after 90 minutes of the absorption process, about $50 \%$ saturation with toluene vapors with simultaneous high efficiency of purification of nitrogen from toluene was obtained.

Furthermore, the DES can be used as low-cost, safe and efficient absorbents with feasible large-scale preparation. Further work will be carried out to perform the regeneration of the DES, in order to recycle them in the absorption step of the process. The DES behavior during the regeneration step will finalize the choice of the absorbent.

\section{References}

1. N. de Arespacochaga, C. Valderram, C. Mesa, L. Bouchy, J. L. Cortina, Chem. Eng. J. 255, 593 (2014)

2. B. Hernández, M. Martín, Ind. Eng. Chem. Res. 55, 6677 (2016)

3. J. Zhou, X. Cao, X. Yong, S. Wang, X. Liu, Y. Chen, T. Zheng, P. Ouyang, Ind. Eng. Chem. Res. 53, 1702 (2014)

4. V. Vrbová, K. Ciahotný, Energy Fuels 31, 9393 (2017)

5. O. Wesley, Y. Zhao, A. Nzihou, D.P. Minh, N. Lyczko, Waste Biomass Valori. 8, 267 (2017)

6. F. M. Baena-Moreno, M. Rodríguez-Galán, F.Vega, L.F. Vilches, B. Navarrete, Int. J. Green Energy 16, 401 (2019)

7. S. Sun, Y. Niu, Q. Xu, Z. Sun, X. Wei, Ind. Eng. Chem. Res. 54, 8019 (2015)

8. Z. Chen, B. McLean, M. Ludwig, R. Stefanovic, G. G. Warr, G. B. Webber, A. J. Page, R. Atkin, J. Phys. Chem. C 120, 2225 (2016)

9. T. Arnold, A. J. Jackson, A. Sanchez-Fernandez, D. Magnone, A. E. Terry, K. J. Edler, Langmuir 31, 12894 (2015)

10. C. M. A. Brett, Curr. Opin. Electrochem. 10, 143 (2018) 
11. A. Abo-Hamad, M. Hayyan, M. A. AlSaadi, M. A. Hashim, Chem. Eng. J. 273, $551(2015)$

12. S. T. Williamson, K. Shahbaz, F. S. Mjalli, I. M. AlNashef, M. M. Farid, Renew. Eng. 114, 480 (2017)

13. S. E. E. Warrag, C. J. Peters, M. C. Kroon, Curr. Opin. Green Sustain. Chem. 5, 55 (2017)

14. P. Makoś, A. Przyjazny, G. Boczkaj, J. Chromatogr. A 1570, 28 (2018)

15. P. Makoś, A. Fernandes, A. Przyjazny, G. Boczkaj, J. Chromatogr. A 1555, 10 (2018)

16. F. Heymes., P. Manno-Demoustier, F. Charbit, J. L. Fanlo, P. Moulin, Chem. Eng. J. 115, 225 (2006)

17. Y. Dai, J. van Spronsen, G. J. Witkamp, R. Verpoorte, Y. H. Choi Anal. Chim. Acta, 766, 61 (2013)

18. A. P. Abbott, D. Boothby, G. Capper, D. L. Davies, R. K. Rasheed J. Am. Chem. Soc. 126, 9142 (2004)

19. Q. Zhang, K. De Oliveira Vigier, S. Royer, F. Jérôme Chem. Soc. Rev. 41, 7108 (2012)

20. S. P. F.Costa, P. C. A. G. Pinto, R. A. S. Lapa, M. L. F. S. Saraiva, J. of Hazardous Materials 284, 136 (2015)

21. M. Cvjetko Bubalo, K. Radošević, I. Radojčić Redovniković, J. Halambek, V. Gaurina Srček, Ecotoxicology and Environmental Safety 99, 1 (2014)

22. R. K. Ibrahim, M. Hayyan, M. A. Alsaadi, S. Ibrahim, A. Hayyan, M. A. Hashim, Studia Ubb Chamia 4, 433 (2017)

23. M. Schiavon, M. Ragazzi, E. C. Rada, V. Torrentta, Crit. Rev. Biotechnol. 36, $1143(2015)$

24. M. Raboni, V. Torretta, G. Urbini, P. Viotti, Waste Manag Res. 33, 48 (2015)

25. Z. X. Zhang, Z. Jiang, W. F. Shangguan, Catal. Today 264, 270 (2016)

26. D. Feng, J. H. Ferrasse, A. Soric, O. Boutin, Chem. Eng. Res. Design 144, 95 (2019)

27. X. Ma, L. Shuo, J. Huang, B. Sun, Y. Zhou, Q. Zhu, H. Lu, Chin. J. Chem. Eng. 1004 (2019) 